\title{
Thermal Enhancement Effects of Buoyancy-Driven Heat Transfer of Hybrid Nanofluid Confined in a Tilted U-Shaped Cavity
}

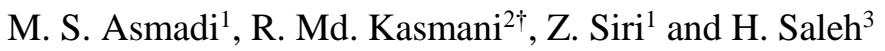 \\ ${ }^{I}$ Institute of Mathematical Sciences, Faculty of Science, Universiti Malaya, 50603, Kuala Lumpur, \\ Malaysia \\ ${ }^{2}$ Mathematics Division, Centre for Foundation Studies in Science, Universiti Malaya, 50603, Kuala Lumpur, \\ Malaysia \\ ${ }^{3}$ Mathematics Education Department, Universitas Islam Negeri Sultan Syarif Kasim, 28293, Pekanbaru, \\ Indonesia \\ $\uparrow$ Corresponding Author Email: ruhaila@um.edu.my
}

(Received April 24, 2021; accepted September 15, 2021)

\begin{abstract}
In this manuscript, the analysis of buoyancy-driven heat transfer of copper-alumina/water hybrid nanofluid in a U-shaped enclosure under the influence of cavity inclination is extensively studied numerically. The dimensionless governing equations are formed by using dimensionless variables. The domain is discretized to a finite number of the Lagrange three-node triangular element, and the finite element method is employed with the Galerkin-weighted residual algorithm to compute and solve the problem. The Newton-Raphson method is employed as a convergence criterion for each iteration. Numerical and experimental validation of the previously published data is conducted with the present results to verify the stability and reliability of the numerical procedure and results. The effect of the lid tilting angle on the heat transfer performance of the enclosure is extensively explored in the manuscript. The streamlines, isotherms, local and average Nusselt numbers as well as the vertical and horizontal velocity of the fluid are plotted for a variation of the Rayleigh number up to $10^{6}$. The analysis of the effect of fluid velocity on the fluid flow and thermal distribution pattern are discussed with relation to the overall heat transfer capability within the domain. It is found that hybrid nanofluid enhances the heat transfer rate within the enclosure. The highest heat transfer performance is at an inclination angle of $40^{\circ} \leq \Theta \leq 60^{\circ}$. The results presented in the manuscript will be useful in the manufacturing processes involving electronics such as laptops and smartphones.
\end{abstract}

Keywords: Buoyancy-driven; Thermodynamics; Hybrid nanofluid; Inclination; U-shaped cavity.

\section{NOMENCLATURE}

$\begin{array}{lll}\mathrm{a} & \text { constant } & \mathrm{u}, \mathrm{V} \\ \mathrm{C}_{\mathrm{p}} & \text { specific heat capacity } & \mathrm{W} \\ \mathrm{g} & \text { acceleration due to gravity } & \mathrm{X}, \mathrm{y} \\ \mathrm{H}_{\mathrm{C}} & \text { cold rib height } & \mathrm{X}, \mathrm{Y} \\ \mathrm{k} & \text { thermal conductivity } & \alpha \\ \mathrm{L}_{\mathrm{c}} & \text { cold rib length } & \beta \\ \mathrm{L}_{\mathrm{H}} & \text { heater element length } & \epsilon \\ \overline{N u} & \text { average Nusselt number } & \Theta \\ \mathrm{Nu}_{l o c} & \text { local Nusselt number } & \theta \\ \mathrm{P} & \text { dimensionless pressure } & \mu \\ \mathrm{p} & \text { pressure } & v \\ \mathrm{Pr} & \text { Prandtl number Rayleigh number } & \rho \\ \mathrm{Re} & \text { Rayleigh number } & \phi \\ \mathrm{T} & \text { temperature } & \left|\Psi_{\max }\right| \\ \mathrm{U}, \mathrm{V} & \text { dimensionless velocity in } \mathrm{x} \text { and } \mathrm{y} & \\ & \text { axis direction } & \end{array}$

\author{
velocity in $\mathrm{x}$ - and $\mathrm{y}$ - axis direction \\ enclosure length and width \\ Cartesian coordinates \\ dimensionless Cartesian coordinates \\ thermal expansion coefficient \\ thermal expansion coefficient \\ tolerance level \\ enclosure inclination angle \\ dimensionless temperature \\ dynamic viscosity \\ kinematic viscosity \\ fluid or particle density \\ nanoparticle volume fraction \\ absolute maximum stream function value
}




\section{INTRODUCTION}

Natural convection or buoyancy-driven heat transfer inside a geometry shape is a well-known research area especially in engineering and thermal physics. The movement of the heat through fluids by means of buoyancy force, which causes the heat convection to occur is a great way to dissipate heat in the applications such as nuclear reactors, smartphones, and even air conditioners. Although this setup achieves a significant heat transfer rate, this application can be optimized by replacing the fluids with nanofluids. Nanofluids are a mixture of a base fluid such as pure water or oil with a type of nanoparticles such as aluminum $(\mathrm{Al})$, titania $\left(\mathrm{TiO}_{2}\right)$, and iron oxide $\left(\mathrm{Fe}_{3} \mathrm{O}_{4}\right)$. The characteristics of the nanofluids especially high thermal conductivity and low chemical reactivity greatly enhance the heat transfer. This method is pioneered by Choi (1995) and has been gaining popularity ever since.

The study of nanofluids' application has been accelerating these days. Roy (2019) reported on the flow and heat transfer analysis within a square cavity with a wavy wall, incorporating nanofluids inside the cavity. He suspended alumina $\left(\mathrm{Al}_{2} \mathrm{O}_{3}\right)$ nanoparticles to the water as his setup and employing the finite difference method (FDM) as a main numerical algorithm throughout the research. Mohebbi et al. (2017) investigated the natural convection fluid flow in an enclosure with a Cshaped filled with nanofluids. The effect of heat source location becomes the main focus of the study. By employing the lattice Boltzmann method (LBM), they noticed that the maximum heat transfer rate is achieved when the heat source is located at the upper horizontal enclosure for Raleigh number of $10^{3}$. Guestal et al. (2018) studied the buoyancydriven heat transfer of two types of nanofluids, namely copper $(\mathrm{Cu})$-water and $\mathrm{TiO}_{2}$-water nanofluids in a cylindrical enclosure with localized heating by employing finite volume method (FVM). They found that the rate of heat transfer increases as the heated wall length increases. Cho et al. (2012) researched the heat transfer analysis of natural convection in a $\mathrm{U}$-shaped enclosure with $\mathrm{Al}_{2} \mathrm{O}_{3}$ water nanofluid as the medium inside the lid. They examined the effects of several parameters such as the nanoparticle volume fraction, the Rayleigh number, and the dimension of the geometry to the average Nusselt number by using FVM. Ma et al. (2019) reported on the effect of the location of hot obstacles on the buoyancy-lid driven heat transfer of multi-walled carbon nanotube (MWCNT)-water nanofluid in a U-shaped cavity by using LBM.

As the researches in the area of nanofluids become deeper, the quest for a more efficient material for heat transfer inside an enclosure becomes increasingly active. Recently, the study of heat transfer is moving towards hybrid nanofluids. Different nanoparticles exhibit a variety of thermal conductivity. There are several other factors to consider when choosing nanoparticles for this purpose, such as the reactivity of the nanoparticles with the base fluids and the procuring cost. Metallic nanoparticles are great in heat transfer but expensive to produce and relatively easy to react with base fluid.

In contrast, metallic oxides are cheaper and relatively stable but have lower thermal conductivity than metallic counterparts. Researchers have found some way to taking advantage of the desirable characteristics of these nanoparticles by mixing both nanoparticle types and suspended on the common base fluid, hence the name hybrid nanofluids. Some examples of hybrid nanofluid are $\mathrm{Cu}-\mathrm{Al}_{2} \mathrm{O}_{3} /$ water and $\mathrm{Al}-\mathrm{TiO}_{2} /$ oil. Studies have shown that this setup has a high thermal conductivity without losing the nanoparticle stability and cost-efficiency.

Although this type of nanofluid is relatively new, there are quite a number of studies have been undergone to exploit the properties of hybrid nanofluids. Hayat and Nadeem (2017) studied the enhancement of the heat transfer performance with silver (Ag) copper oxide $(\mathrm{CuO}) /$ water hybrid nanofluid on a three-dimensional space by employing the bvp4c technique coupled with the shooting method. They agreed that the heat transfer performance of the hybrid nanofluid used is significantly greater than $\mathrm{Ag} /$ water and $\mathrm{CuO}$ /water nanofluids. Tayebi and Chamkha (2017) reported on the natural convection analysis of heat transfer in an enclosure with sinusoidal heating by incorporating $\mathrm{Cu}-\mathrm{Al}_{2} \mathrm{O}_{3} /$ water hybrid nanofluid. They used FVM to solve the problem numerically and found that the positive feedback of hybrid nanofluid is greater at high Rayleigh numbers. Ashorynejad (2018) investigated the magnetohydrodynamic (MHD) natural convection of water-based hybrid nanofluid with $\mathrm{Cu}-\mathrm{Al}_{2} \mathrm{O}_{3}$ nanoparticles embedded in an open cavity by using LBM. He noted that the average heat transfer rate decreases with the increase of the Hartmann number but the opposite is observed as the Rayleigh number increases from $10^{3}$ to $10^{5}$. Hassan et al. (2018) researched the reaction of $\mathrm{CuAg} /$ water hybrid nanofluid on the boundary layer flow over the wedge. They examined the effect of nanoparticle volume fraction and different compositions of hybrid nanoparticles on the heat transfer performance of the fluid by employing the homotopy analysis method (HAM). Al-srayyih et al. (2019) published on the buoyancy-driven analysis of a hybrid nanofluid within a partially porous square cavity employing a thermal non-equilibrium model. By utilizing the finite element method (FEM), they reported that the local heat transfer rate decreases as the length of the heating element increases, with an asymmetric distribution, is observed at the heated wall. Tayebi and Chamkha (2020) studied the buoyancy-driven analysis on the heat transfer of hybrid nanofluid within a square cavity with a wavy circular cylinder and magnetic field. The FVM is used to solve the problem numerically and varies the amplitude and the frequency of the wavy circular wall to explore its effects on the average heat transfer performance.

Inspired by the previous researches, this paper aimed to focus on the study of buoyancy-driven heat transfer analysis of water-based hybrid nanofluid embedded with $\mathrm{Cu}-\mathrm{Al}_{2} \mathrm{O}_{3}$ nanoparticles in an inclined U-shaped lid. The study on an inclined cavity is important and useful for manufacturing 
processes and industries where space-saving measures have to be implemented to decrease the overall dimension of the product, such as heat exchangers, smartphones, laptops, and nuclear reactors. This is due to when the upright U-shaped lid is impossible to implement. It is also possible for the present result to be used when the manufacturers want to find a configuration where the maximum heat transfer rate is needed. The dimensionless variables are applied to form a set of dimensionless governing equations. A robust Galerkin weighted residual three-node triangular FEM is employed to solve the system, with the damped Newton-Raphson method as the convergence criterion. The effect of the Rayleigh number, the nanoparticle volume fraction, and the enclosure inclination angle are extensively reported and analyzed by varying and fixing the parameters involved. The average and local Nusselt numbers are used as a means to measure the heat transfer rate within the enclosure locally and globally.

\section{MATHEMATICAL LATION}

FORMU-

In this paper, an inclined U-shaped square enclosure with $\mathrm{Cu}-\mathrm{Al}_{2} \mathrm{O}_{3} /$ water hybrid nanofluid filling the cavity with the length and height of $W$ is depicted in Fig. 1. The walls EF, FG, and GJ are collectively denoted as the cold rib and has the dimension of $L_{C}$ and $H_{C}$ as the length and height, respectively. By fixing where $T_{H}>T_{C}$, the wall $\mathrm{BC}$ located at the bottom of the enclosure is heated with a constant temperature of $T_{H}$ and the cold rib EFGJ is cooled with a constant temperature $T_{C}$. The remaining walls are kept adiabatic. The cavity is tilted at some angle $\Theta$ from the horizontal plane. The velocity of the nanofluid $u$ and $v$ are in the direction of $x$ - and $y$ axis respectively, and the enclosure is under the influence of the gravitational acceleration $g$ in the vertical direction. By employing Boussinesq approximation, the governing equations of the problem in the dimensionless form are,

$$
\begin{aligned}
\frac{\partial \mathrm{U}}{\partial \mathrm{X}}+\frac{\partial \mathrm{V}}{\partial \mathrm{Y}}=0 & \begin{aligned}
\mathrm{U} \frac{\partial \mathrm{U}}{\partial \mathrm{X}}+\mathrm{V} \frac{\partial \mathrm{U}}{\partial \mathrm{Y}}=-\frac{\partial \mathrm{P}}{\partial \mathrm{X}} & +\frac{\mu_{\mathrm{hnf}}}{\rho_{\mathrm{hnf}} \alpha_{\mathrm{bf}}}\left(\frac{\partial^{2} \mathrm{U}}{\partial \mathrm{X}^{2}}+\frac{\partial^{2} \mathrm{U}}{\partial \mathrm{Y}^{2}}\right) \\
& +\operatorname{RaPr} \theta \frac{(\rho \beta)_{\mathrm{hnf}}}{\rho_{\mathrm{hnf}} \beta_{\mathrm{bf}}} \sin \Theta
\end{aligned}
\end{aligned}
$$

$$
\begin{aligned}
\mathrm{U} \frac{\partial \mathrm{V}}{\partial \mathrm{X}}+\mathrm{V} \frac{\partial \mathrm{V}}{\partial \mathrm{Y}}=-\frac{\partial \mathrm{P}}{\partial \mathrm{Y}} & +\frac{\mu_{\mathrm{hnf}}}{\rho_{\mathrm{hnf}} \alpha_{\mathrm{bf}}}\left(\frac{\partial^{2} \mathrm{~V}}{\partial \mathrm{X}^{2}}+\frac{\partial^{2} \mathrm{~V}}{\partial \mathrm{Y}^{2}}\right) \\
& +\operatorname{RaPr} \theta \frac{(\rho \beta)_{\mathrm{hnf}}}{\rho_{\mathrm{hnf}} \beta_{\mathrm{bf}}} \cos \Theta
\end{aligned}
$$$$
\mathrm{U} \frac{\partial \theta}{\partial \mathrm{X}}+\mathrm{V} \frac{\partial \theta}{\partial \mathrm{Y}}=+\frac{\alpha_{\mathrm{hnf}}}{\alpha_{\mathrm{bf}}}\left(\frac{\partial^{2} \theta}{\partial \mathrm{X}^{2}}+\frac{\partial^{2} \theta}{\partial \mathrm{Y}^{2}}\right)
$$

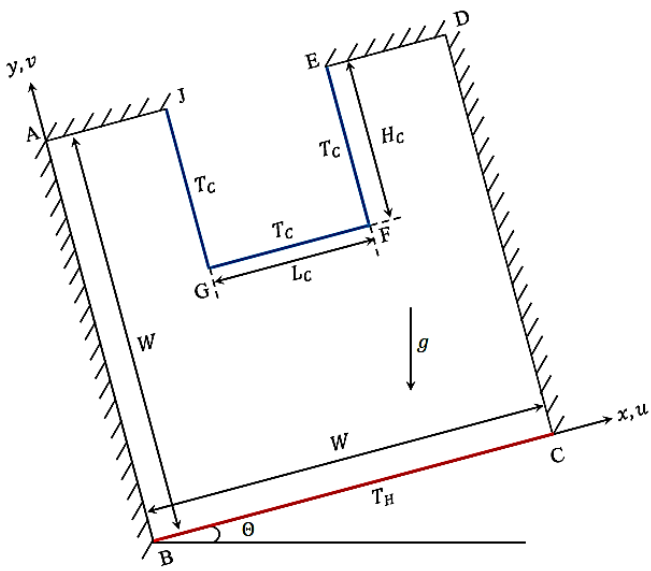

Fig. 1. Schematic geometry of the U-shaped enclosure used in the study.

where $\operatorname{Pr}=v_{b f} / \alpha_{b f}$ is the Prandtl number and Ra $=\left[g \beta_{b f} W^{3}\left(T_{H}-T_{C}\right)\right] / \alpha_{b f} v_{b f}$ is the Rayleigh number. Throughout the paper, the subscripts $h n f$ denoted the quantity related to the hybrid nanofluid, $b f$ is for the base fluid and $h p$ is for the hybrid nanoparticles. The following dimensionless variables are used in order to transform Eqs. (1) - (4),

$$
\begin{gathered}
X=\frac{\mathrm{x}}{\mathrm{W}}, \quad \mathrm{Y}=\frac{\mathrm{y}}{\mathrm{W}}, \quad \mathrm{U}=\frac{\mathrm{uW}}{\alpha_{\mathrm{bf}}}, \quad \mathrm{V}=\frac{\mathrm{vW}}{\alpha_{\mathrm{bf}}}, \\
\mathrm{P}=\frac{\mathrm{pW}}{\rho_{\mathrm{bf}} \alpha_{\mathrm{bf}}^{2}}, \quad \theta=\frac{\mathrm{T}-\mathrm{T}_{\mathrm{C}}}{\mathrm{T}_{\mathrm{H}}-\mathrm{T}_{\mathrm{C}}}
\end{gathered}
$$

where $\mathrm{T}, \alpha=\mathrm{k} / \rho \mathrm{C}_{\mathrm{p}}, \rho, \mathrm{C}_{\mathrm{p}}, \beta, \mathrm{k}, \mu$, and $v$ are the temperature, thermal diffusivity, material density, heat capacity, thermal expansion coefficient, thermal conductivity, dynamic viscosity, and kinematic viscosity respectively. The thermophysical properties of the base fluid and nanoparticles from Snoussi et al. (2017) are shown in Table 1. The dimensionless velocity and thermal boundary conditions to be imposed to the cavity shown in Fig. 1 are,

$\mathrm{U}=\mathrm{V}=0$ at all walls

$\theta=1$ at wall $B C$

$\theta=0 \quad$ at walls $E F, F G$ and $G J$

$\frac{\partial \theta}{\partial \mathrm{X}}=0$ at walls $A B$ and $C D$

$\frac{\partial \theta}{\partial \mathrm{Y}}=0 \quad$ at walls $\mathrm{DE}$ and $\mathrm{JA}$

The hybrid nanoparticle volume fraction $\phi_{\mathrm{hp}}$, hybrid density $\rho_{\mathrm{hp}}$, hybrid thermal conductivity $\mathrm{k}_{\mathrm{hp}}$ , hybrid thermal expansion coefficient $\beta_{\mathrm{hp}}$ and hybrid heat capacity $\left(\mathrm{C}_{\mathrm{p}}\right)_{\mathrm{hp}}$ respectively are, 
Table 1. Thermophysical properties of the base fluid and nanoparticles (Snoussi et al. 2017).

\begin{tabular}{|l|c|c|c|}
\hline Materials & Water & $\mathrm{Cu}$ & $\mathrm{Al} 2 \mathrm{O} 3$ \\
\hline $\begin{array}{l}C_{p}(\mathrm{~J} \\
\mathrm{kg}-{ }^{1} \mathrm{~K}-1\end{array}$ & 4179 & 385 & 765 \\
\hline $\begin{array}{l}\rho(\mathrm{kg} \\
\left.\mathrm{m}^{-3}\right)\end{array}$ & 997.1 & 8933 & 3970 \\
\hline $\begin{array}{l}k(\mathrm{~W} \\
\left.\mathrm{m}^{-1} \mathrm{~K}^{-1}\right)\end{array}$ & 0.613 & 401 & 40 \\
\hline$\beta\left(\mathrm{K}^{-1}\right)$ & 21 & $1.67 \times 10^{-5}$ & $0.85 \times 10^{-5}$ \\
\hline
\end{tabular}

$\phi_{\mathrm{hp}}=\phi_{\mathrm{Cu}}+\phi_{\mathrm{Al}_{2} \mathrm{O}_{3}}$

$\rho_{\mathrm{hp}}=\frac{\phi_{\mathrm{Cu}} \rho_{\mathrm{Cu}}+\phi_{\mathrm{Al}_{2} \mathrm{O}_{3}} \rho_{\mathrm{Al}_{2} \mathrm{O}_{3}}}{\phi_{\mathrm{hp}}}$

$\mathrm{k}_{\mathrm{hp}}=\frac{\phi_{\mathrm{Cu}} \mathrm{k}_{\mathrm{Cu}}+\phi_{\mathrm{Al}_{2} \mathrm{O}_{3}} \mathrm{k}_{\mathrm{Al}_{2} \mathrm{O}_{3}}}{\phi_{\mathrm{hp}}}$

$\beta_{\mathrm{hp}}=\frac{\phi_{\mathrm{Cu}} \beta_{\mathrm{Cu}}+\phi_{\mathrm{Al}_{2} \mathrm{O}_{3}} \beta_{\mathrm{Al}_{2} \mathrm{O}_{3}}}{\phi_{\mathrm{hp}}}$

$\left(\mathrm{C}_{\mathrm{p}}\right)_{\mathrm{hp}}=\frac{\phi_{\mathrm{Cu}}\left(\mathrm{C}_{\mathrm{p}}\right)_{\mathrm{Cu}}+\phi_{\mathrm{Al}_{2} \mathrm{O}_{3}}\left(\mathrm{C}_{\mathrm{p}}\right)_{\mathrm{Al}_{2} \mathrm{O}_{3}}}{\phi_{\mathrm{hp}}}$

The effective specific heat capacity $\left(\rho C_{p}\right)_{h n f}$, effective thermal expansion coefficient $\beta_{\mathrm{hnf}}$, effective density $\rho_{\text {hnf }}$ and effective thermal diffusivity $\alpha_{\text {hnf }}$ respectively are,

$\left(\rho \mathrm{C}_{\mathrm{p}}\right)_{\mathrm{hnf}}=\left(1-\phi_{\mathrm{hp}}\right)\left(\rho \mathrm{C}_{\mathrm{p}}\right)_{\mathrm{bf}}+\phi_{\mathrm{hp}}\left(\rho \mathrm{C}_{\mathrm{p}}\right)_{\mathrm{hp}}$

$\beta_{\mathrm{hnf}}=\left(1-\phi_{\mathrm{hp}}\right) \beta_{\mathrm{bf}}+\phi_{\mathrm{hp}} \beta_{\mathrm{hp}}$

$\rho_{\mathrm{hnf}}=\left(1-\phi_{\mathrm{hp}}\right) \rho_{\mathrm{bf}}+\phi_{\mathrm{hp}} \rho_{\mathrm{hp}}$

$\alpha_{\mathrm{hnf}}=\frac{\mathrm{k}_{\mathrm{hnf}}}{\left(\rho \mathrm{C}_{\mathrm{p}}\right)_{\mathrm{hnf}}}$

The effective dynamic viscosity $\mu_{\mathrm{hn} \text { f given by }}$ Brinkman (1952) is,

$\mu_{\mathrm{hnf}}=\frac{\mu_{\mathrm{bf}}}{\left(1-\phi_{\mathrm{hp}}\right)^{2.5}}$

From Hamilton and Crosser (1962), the ratio of thermal conductivity of the hybrid nanofluid is,

$\frac{\mathrm{k}_{\mathrm{hnf}}}{\mathrm{k}_{\mathrm{bf}}}=\frac{\mathrm{k}_{\mathrm{hp}}+2 \mathrm{k}_{\mathrm{bf}}-2 \phi_{\mathrm{hp}}\left(\mathrm{k}_{\mathrm{bf}}-\mathrm{k}_{\mathrm{hp}}\right)}{\mathrm{k}_{\mathrm{hp}}+2 \mathrm{k}_{\mathrm{bf}}+\phi_{\mathrm{hp}}\left(\mathrm{k}_{\mathrm{bf}}-\mathrm{k}_{\mathrm{hp}}\right)}$

As a means to measure the heat transfer performance within the enclosure, the local and average Nusselt numbers are introduced. The rate of heat transfer at a local position relative to the wall is denoted as $\mathrm{Nu}_{\text {loc }}$ , where,

$N u_{l o c}=-\frac{\mathrm{k}_{\mathrm{hnf}}}{\mathrm{k}_{\mathrm{bf}}} \frac{\partial \theta}{\partial \mathrm{Y}}$

The average rate of heat transfer, $\overline{N u}$ along the heated wall $\mathrm{BC}$ is,

$\overline{N u}=\int_{0}^{1} N u_{l o c} d \mathrm{X}$

\section{METHOD OF SOLUTION}

The governing equations in Eqs. (1) - (4) along with prescribed boundary conditions in Eqs. (6) - (10) are discretized and computed using a robust threenode Lagrange triangular FEM (Bhatti (2005)). Figure 2 shows an example of the meshing done by the triangular discretization. The Galerkin weighted residual FEM is chosen to calculate and compute the physical quantities needed for the analysis. The nonlinear nature of the governing equations is transformed into a set of linear equations by applying a chosen weight function. The set of equations are then coupled and evaluated at each triangular nodal point within the domain of the enclosure to get the initial value using the boundary conditions in Eqs. (6) - (10). The equations are then assembled into a matrix, and the LU decomposition algorithm is used to solve the matrix. The damped Newton-Raphson method ((Buchanan and Fitzgibbon (2005))) is used iteratively after each FEM iteration until the residuals are within the tolerance level of $\epsilon=10^{-3}$.

An extensive mesh independency test is performed to ascertain a grid independent solution. Table 2 depicts several mesh configurations with the resulting average Nusselt number, $\overline{N u}$ and maximum stream function value, $\left|\Psi_{\max }\right|$ with $\mathrm{H}_{\mathrm{C}}=\mathrm{L}_{\mathrm{C}}=0.5, \phi_{\mathrm{Cu}}=0.03, \phi_{\mathrm{Al}_{2} \mathrm{O}_{3}}=0.03, \Theta=60^{\circ}$

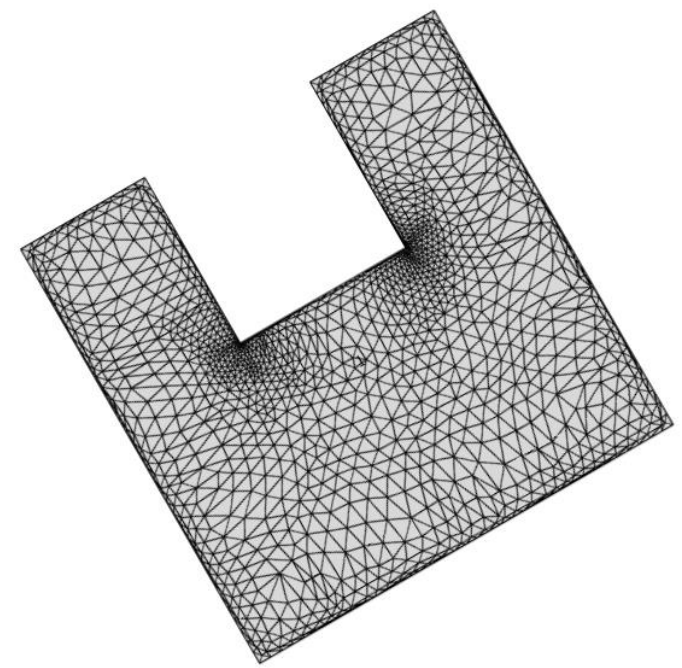

Fig. 2. A triangular discretisation of the Ushaped enclosure. 
Table 2. The values of $\overline{N u},\left|\Psi_{\max }\right|$ and corresponding percentage residuals for several meshing type

\begin{tabular}{|c|c|c|c|c|c|}
\hline \multirow{2}{*}{ Meshing type } & \multirow{2}{*}{$\begin{array}{c}\text { Number of } \\
\text { triangular elements }\end{array}$} & \multicolumn{2}{|c|}{$\overline{N u}$} & \multicolumn{2}{c|}{$\mid \Psi_{\text {max }}$} \\
\cline { 3 - 5 } & & Value & \% residuals & Value & \% residuals \\
\hline I & 354 & 9.759 & 0.000000 & 31.5054 & 0.000000 \\
\hline II & 584 & 9.991 & 2.319087 & 29.8498 & 5.546162 \\
\hline III & 856 & 10.092 & 1.000793 & 28.7587 & 3.793942 \\
\hline IV & 1546 & 10.138 & 0.453738 & 27.9025 & 3.068796 \\
\hline V & 2160 & 10.174 & 0.353843 & 27.4079 & 1.804554 \\
\hline VI & 3364 & 10.183 & 0.088383 & 27.0448 & 1.342476 \\
\hline VII & 8854 & 10.176 & 0.068789 & 26.8593 & 0.690523 \\
\hline VIII & 22752 & 10.177 & 0.009826 & 26.7568 & 0.383192 \\
\hline IX & 28084 & 10.178 & 0.009825 & 26.7315 & 0.094795 \\
\hline
\end{tabular}

and $\mathrm{Ra}=10^{6}$. Based on Table 2, meshing type VII are chosen because the percentage residuals of $\overline{\mathrm{Nu}}$ and $\left|\Psi_{\max }\right|$ for meshing type VIII are within $1 \%$. That means the subsequent increment of the number of elements does not significantly improve the results with longer computational time. This is to ensure that the results are within the tolerance level without compensating the computational time.

Table 3 presents the comparison of the average Nusselt number $\overline{N u}$ for various Rayleigh number, Ra between Makulati et al. (2016) and the present study for $\mathrm{Al}_{2} \mathrm{O}_{3} /$ water nanofluid with $\mathrm{H}_{\mathrm{C}}=\mathrm{L}_{\mathrm{C}}=0.4, \phi_{\mathrm{hp}}=0$ and 0.04 , and three-walled heated wall, which located at the walls $\mathrm{AB}, \mathrm{BC}$ and $\mathrm{CD}$ at $\Theta=-90^{\circ}$. In their paper, Makulati et al. (2016) used FVM with Semi-Implicit Method for Pressure-Linked Equation (SIMPLE) algorithm to solve the system in the research. Excellent agreement between both results are observed, as shown in Table 3. This observation ensures confidence on the numerical code and mathematical calculations performed in this study.

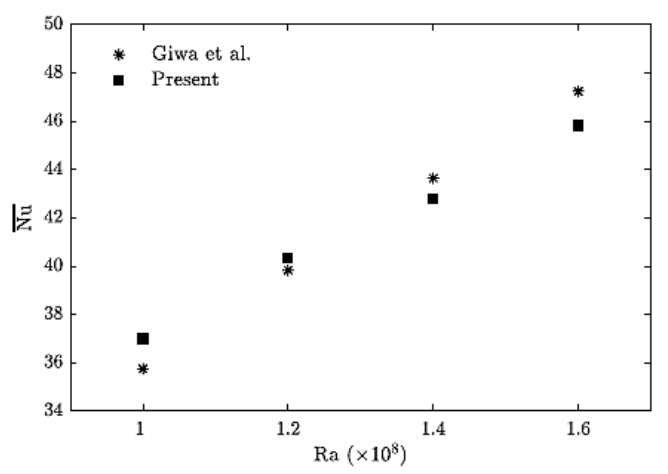

Fig. 3. Values of $\overline{N u}$ from Giwa et al. (2020) with the present numerical computations.
To assure the numerical stability and reliability of the numerical modeling and computed results, a comparison between the present results with the experimental results published by Giwa et al. (2020) is done and presented in Fig.3. The numerical simulation is replicated with the same experimental setup for a square enclosure with a heating and cooling wall at the sides filled with an equal ratio of $\mathrm{Al}_{2} \mathrm{O}_{3}$-multi-walled carbon nanotubes (MWCNT)/water hybrid nanofluids with $\phi=0.1$. From Fig. 3, a good agreement of the values of $\overline{\mathrm{Nu}}$ for $1 \times 10^{8} \leq \mathrm{Ra} \leq 1.6 \times 10^{8}$ is observed. This observation assures the reliability of the system modeling and the numerical algorithm produced for the current manuscript.

\section{RESULTS AND DISCUSSION}

In this paper, the ratio of nanoparticle volume fraction is fixed at $1: 1$, unless stated otherwise. This means if $\phi_{\mathrm{hp}}=\mathrm{a}$ where $\mathrm{a}$ is a real number, then $\phi_{\mathrm{Cu}}=\phi_{\mathrm{Al}_{2} \mathrm{O}_{3}}=\mathrm{a} / 2$.

The variation of average Nusselt number $\overline{N u}$ for nanoparticle volume fraction of $0 \leq \phi_{\mathrm{hp}} \leq 0.1$ with $10^{4} \leq R a \leq 10^{6}, \mathrm{H}_{\mathrm{C}}=\mathrm{L}_{\mathrm{C}}=0.4$ and $\Theta=60^{\circ}$ are plotted in Fig. 4a. It can be seen that the value of $\overline{\mathrm{Nu}}$ is increasing with the increasing of $\phi_{\mathrm{hp}}$ for all $\mathrm{Ra}$, but it is more significant when $\mathrm{Ra}=10^{6}$. That means the addition of hybrid nanoparticle to the base fluid is more suitable in the fluid of higher Ra in terms of the heat transfer rate. In Fig. 4b, the variation of average Nusselt number against the nanoparticle volume fraction for different types of nanofluids are plotted with $\mathrm{H}_{\mathrm{C}}=\mathrm{L}_{\mathrm{C}}=0.4$ and $\Theta=60^{\circ}$ for $\mathrm{Ra}=10^{4}$. Based on Fig. $4 \mathrm{~b}$, the value of $\overline{N u}$ is about the same for $0 \leq \phi_{\mathrm{hp}} \leq 0.01$, but it diverges and increases 


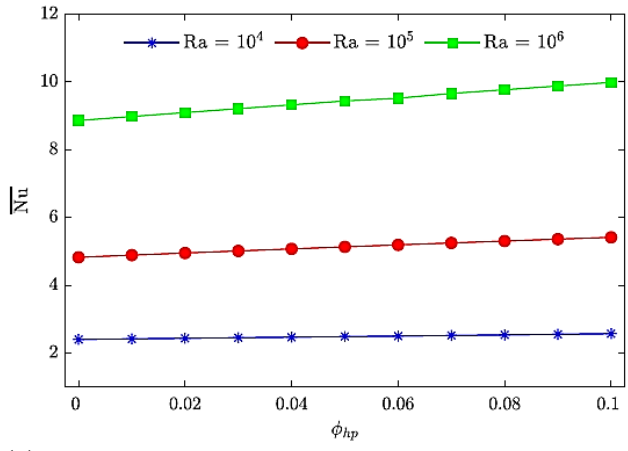

(a)

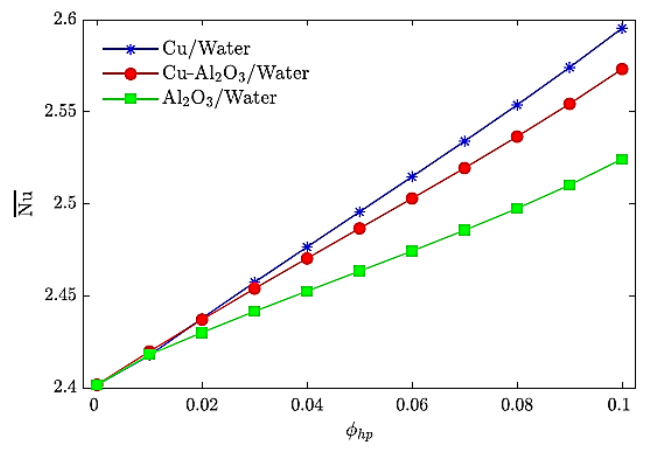

(b)

Fig. 4. Effect of the nanoparticle volume fraction to the average Nusselt number at the hot wall with (a) different Rayleigh number; (b) different type of nanofluids and hybrid nanofluids with

$$
\mathbf{H}_{\mathrm{C}}=\mathbf{L}_{\mathbf{C}}=\mathbf{0 . 4} ; \Theta=60^{\circ} \text { and } \mathbf{R a}=\mathbf{1 0}^{4} \text {. }
$$

when $\phi_{\mathrm{hp}} \geq 0.02$. The value of $\overline{N u}$ for $\mathrm{Cu} /$ water nanofluid is increasing at the higher rate while $\mathrm{Al}_{2} \mathrm{O}_{3} /$ water nanofluid is the lowest. It is noted that the value of $\overline{N u}$ for $\mathrm{Cu}-\mathrm{Al}_{2} \mathrm{O}_{3} /$ water hybrid nanofluid is closer to $\mathrm{Cu} /$ water nanofluids as $\phi_{\mathrm{hp}}$ increases. This means the addition of $\mathrm{Cu}$ nanofluid particles inside $\mathrm{Al}_{2} \mathrm{O}_{3}$ /water nanofluid increases the heat transfer rate. The heat transfer rate of $\mathrm{Al}_{2} \mathrm{O}_{3}$ /water nanofluid is also comparable to $\mathrm{Cu}$ /water nanofluids with a cheaper cost. As the value of $\phi_{\mathrm{hp}}$ increases, the value of $\overline{\mathrm{Nu}}$ for $\mathrm{Cu}-$ $\mathrm{Al}_{2} \mathrm{O}_{3}$ /water hybrid nanofluid increases at a higher rate compared to $\mathrm{Al}_{2} \mathrm{O}_{3}$ /water nanofluid.

Figure 5 shows the effect of different nanoparticle volume fraction ratios to the average Nusselt number $\overline{N u}$ with $\phi_{\mathrm{hp}}=0.1, \mathrm{H}_{\mathrm{C}}=\mathrm{L}_{\mathrm{C}}=0.4$ and $\Theta=60^{\circ}$ for $\mathrm{Ra}=10^{4}$ and $\mathrm{Ra}=10^{6}$. In Fig. 5a, for $\mathrm{Ra}=10^{4}$, replacing $10 \backslash \%$ of $\mathrm{Al}_{2} \mathrm{O}_{3}$ by volume with $\mathrm{Cu}$ nanoparticles in $\mathrm{Al}_{2} \mathrm{O}_{3}$ /water nanofluids (indicated by the ratio of $\phi_{\mathrm{Cu}}: \phi_{\mathrm{Al}_{2} \mathrm{O}_{3}}=0.01: 0.09$ ), the heat transfer rate is greatly increase inside the enclosure. While the succeeding replacement of nanoparticle increase the value of $\overline{N u}$, the rate is diminishing. This means that for lower Ra, substituting about $10 \backslash \%$ by volume of $\mathrm{Al}_{2} \mathrm{O}_{3}$ nanoparticle with $\mathrm{Cu}$ nanoparticles is the best way to increase the heat

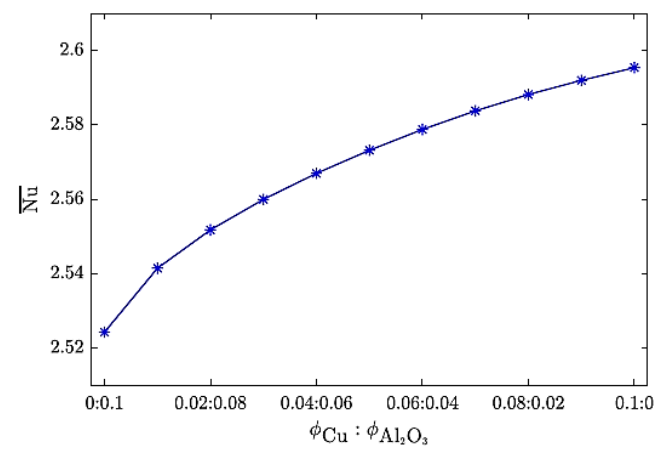

(a)

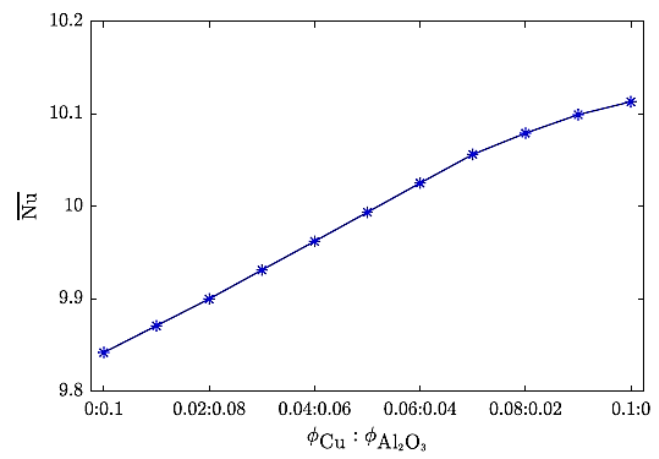

(b)

Fig. 5. Effect of different nanoparticle volume fraction ratios of $\mathrm{Cu}$ and $\mathrm{Al} 2 \mathrm{O3}$ to the average Nusselt number at the hot wall with $\mathbf{H}_{\mathrm{C}}=\mathrm{L}_{\mathrm{C}}$

$=0.4 ; \Theta=60^{\circ}$ for $(\mathbf{a}) \mathbf{R a}=10^{4}$; (b) $\mathbf{R a}=\mathbf{1 0}^{6}$.

transfer rate with a fraction of cost of that $\mathrm{Cu}$ has. In Fig. $5 \mathrm{~b}$ (when $\mathrm{Ra}=10^{6}$ ), it is found that the values of $\overline{N u}$ are increasing about at the same rate as $\overline{N u}$ in Fig. $5 \mathrm{a}$ (when $\mathrm{Ra}=10^{4}$ ). This concludes that as $\phi_{\mathrm{Cu}}$ vincreases, the thermal performance of $\mathrm{Cu}$ $\mathrm{Al}_{2} \mathrm{O}_{3}$ /water hybrid nanofluid increases.

Figure 6 shows the effects of the enclosure inclination angle and the dimension of the cold rib to the streamlines of the fluid flow inside the enclosure for $\mathrm{Ra}=10^{6}$ and $\phi_{\mathrm{hp}}=0.05$. Based on Fig. 6, the streamlines inside the enclosure produce two symmetrical Rayleigh-Benard cells for $\Theta=0^{\circ}$ and $0.2 \leq \mathrm{L}_{\mathrm{C}}=\mathrm{H}_{\mathrm{C}} \leq 0.6$, and six cells for $\mathrm{L}_{\mathrm{C}}=\mathrm{H}_{\mathrm{C}}=0.8$. The force due to gravity is pulling the fluid in a symmetrical direction in terms of the enclosure shape and producing those symmetrical cells. The six cells produced for $\mathrm{L}_{\mathrm{C}}=\mathrm{H}_{\mathrm{C}}=0.8$ are due to the long and narrow enclosure space in the horizontal direction. The buoyancy force of the fluid is not able to overcome the gravity force for the entire length of the horizontal wall, so the fluid moves in smaller cells and producing a higher number of Rayleigh-Benard cells. For a fixed cold rib dimension, as $\Theta$ increases, the fluid is moving in one big cell, circling the whole enclosure. As $\Theta$ increases, the hot wall moves from the bottom to the 

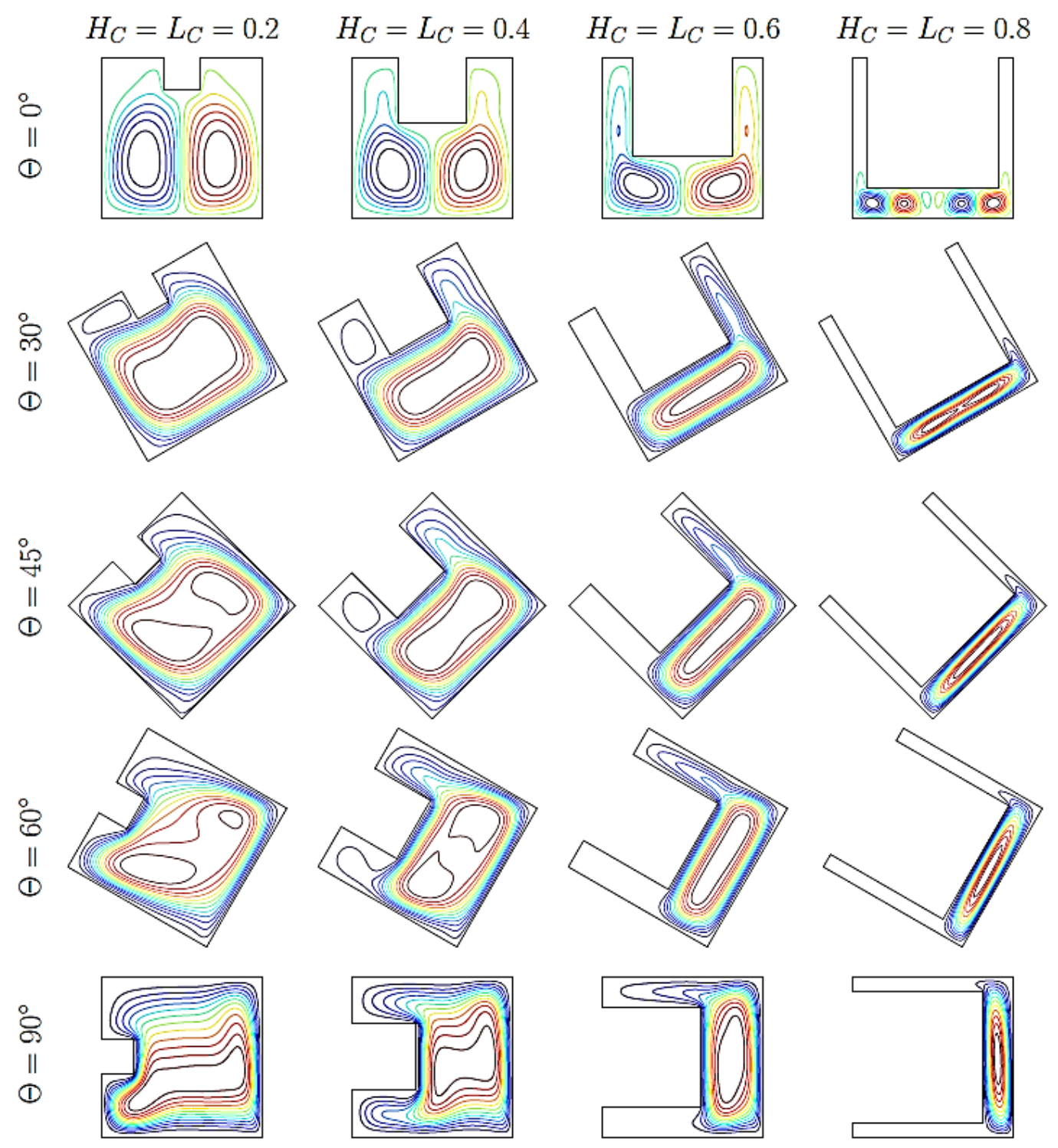

Fig. 6. Streamlines of the hybrid nanofluid with different enclosure inclination angle and the dimension of the cold rib with $R a=10^{6}$ and $\phi_{\mathrm{hp}}=\mathbf{0 . 0 5}$.

right. This motion causes the buoyancy force to move the fluid along the hot wall towards corner $\mathrm{C}$ rather than directly towards the cold rib. This situation forces the velocity of the fluid to decrease as $\Theta$ increases. At wall $\mathrm{CD}$, with lower $\Theta$, the streamlines are close together due to the buoyancy force and the fluid flows directly to the entire wall CD. At $\Theta=90^{\circ}$, the hot wall is perpendicular to the gravity force, which causes the fluid to flow along the hot wall towards the corner $\mathrm{C}$, before traveling along wall $\mathrm{CD}$ and completes the anticlockwise circling. This causes the streamlines along wall CD to be further apart at $\Theta=90^{\circ}$ and the fluid flow at a higher velocity near the hot wall but lower velocity near the wall $C D$. For a constant $\Theta$, the streamlines reach the left cold rib lesser as the cold rib dimension increases. This phenomenon occurs because there is no hot wall at the bottom of the cold rib area. The hot wall which produces buoyancy force is not present there as $\mathrm{L}_{\mathrm{C}}=\mathrm{H}_{\mathrm{C}}$ increases, causes the fluid to flow elsewhere in the enclosure. In turn, the heat dissipates lesser at the cold wall GJ than the other cold walls EF and FG.

Figure 7 shows the effect of the inclination angle and the dimension of the cold rib to the isotherms of the fluid flow inside the enclosure for $\mathrm{Ra}=10^{6}$ and $\phi_{\text {hp }}=0.05$. At $\Theta=0^{\circ}$, the isotherms are symmetrical about $\mathrm{X}=0.5$ for all $\mathrm{L}_{\mathrm{C}}=\mathrm{H}_{\mathrm{C}}$ due to the symmetrical nature of the enclosure and the force due to gravity present in the enclosure. The hot fluid from the bottom of the enclosure travels to the top due to the higher buoyancy force at the higher Ra at the side of the wall because of the presence of the cold rib at the middle of the top portion of the 

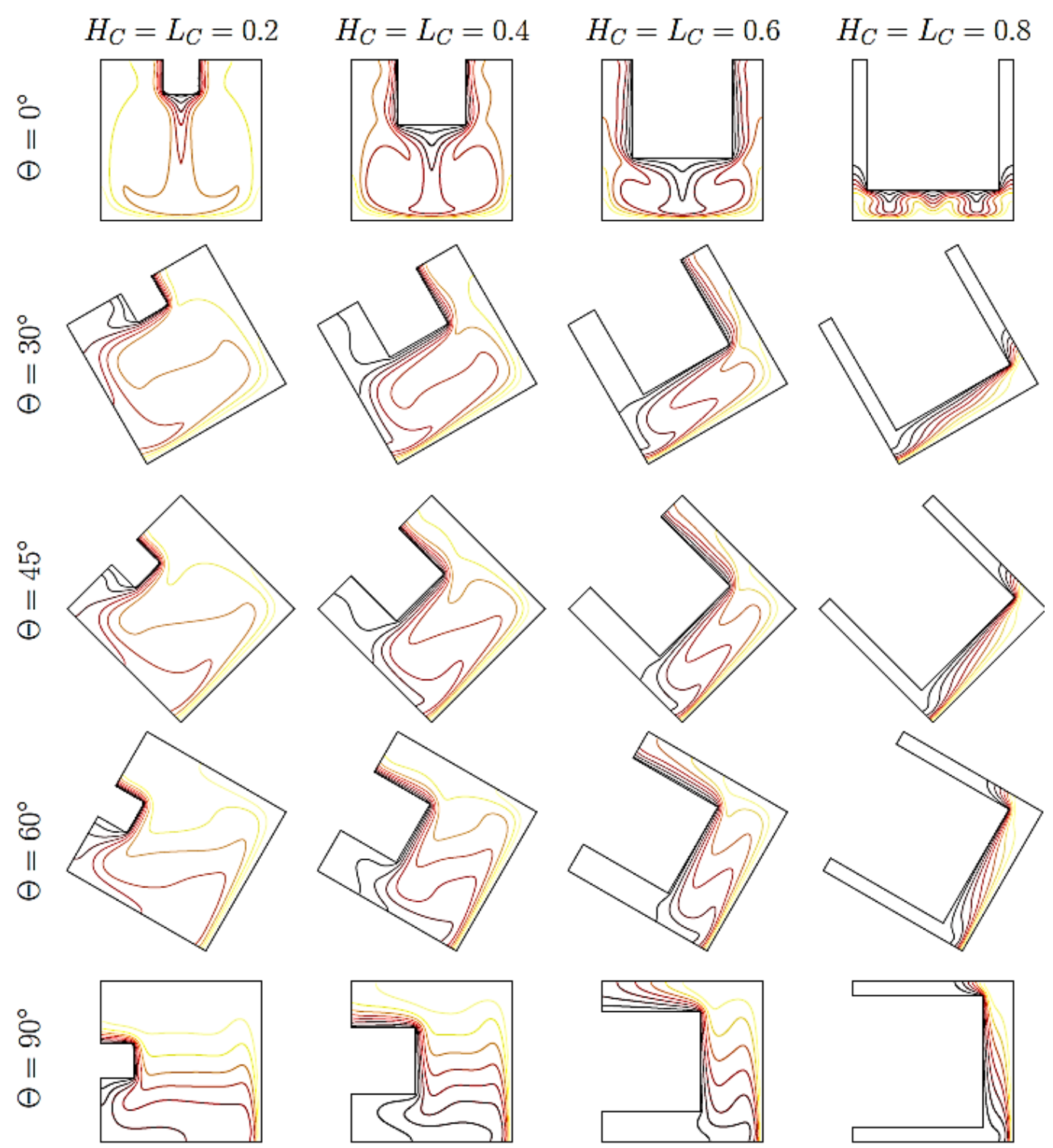

Fig. 7. Isotherms of the hybrid nanofluid with different enclosure inclination angle and the dimension of the cold rib with $\mathrm{Ra}=10^{6}$ and $\phi_{\mathrm{hp}}=\mathbf{0 . 0 5}$.

enclosure. The cold rib makes the distance from the hot wall to the cold wall at the top shorter and the cold wall FG are significantly lower than the wall DE and JA, so the less dense hot fluid tends to move to the higher cavity due to the buoyancy force. The denser cold fluid then flows downwards at the middle of the enclosure in a symmetrical manner as the hot fluid pushes the cold fluid in this manner. This phenomenon occurs at all cold rib dimension for $\Theta=0^{\circ}$ except for $\mathrm{L}_{\mathrm{C}}=\mathrm{H}_{\mathrm{C}}=0.8$. The narrow cavity causes the cold fluid to flow towards the hot wall in two places; at about $X=0.25$ and $X=0.75$. As $\Theta$ increases, the isotherms become more parallel to the hot wall and the cold wall FG. The direction of force due to gravity is moving towards wall $\mathrm{AB}$ as $\Theta$ increases, causes the less dense hot fluid to move along the hot wall towards wall CD and the denser cold fluid to move along cold wall FG towards wall $\mathrm{AB}$. At the center of the enclosure, the isotherms become more parallel to the wall $\mathrm{AB}$ and $\mathrm{CD}$ as $\Theta$ increases due to lesser buoyancy force and greater gravitational force present in the direction perpendicular to the walls $\mathrm{AB}$ and $\mathrm{CD}$. This situation causes the heat transfer of the fluid to behaves like conduction at the middle of the enclosure.

Figure 8 presents the combined plots of velocity vectors with its magnitude and isosurface with $\Theta=60^{\circ}, \mathrm{H}_{\mathrm{C}}=\mathrm{L}_{\mathrm{C}}=0.5, R a=10^{6}$ and $\phi_{\mathrm{hp}}=0.06$. In

Fig. $8 \mathrm{a}$, the red area denotes higher fluid velocity while the blue area denotes lower velocity. The highest fluid velocity is at the area near the cold wall FG and the hot wall. This is due to the buoyancy force acting on the fluid cause the fluid to move at a higher velocity near the hot wall, and the presence of force due to gravity forces the fluid to move faster near the cold wall FG. A higher fluid velocity is also present at the lower area of adiabatic walls $\mathrm{AB}$ and $\mathrm{CD}$. The resulting gravitational and buoyancy forces acting on the fluid at this area cause the fluid to move 


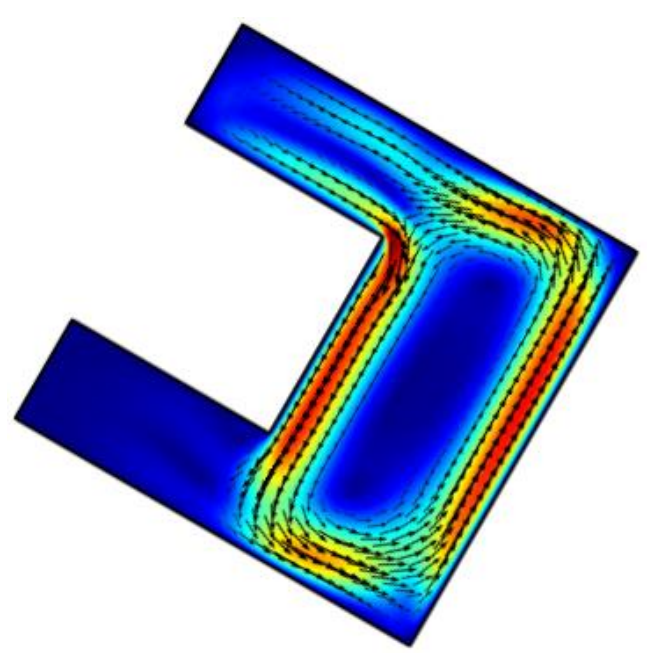

(a)

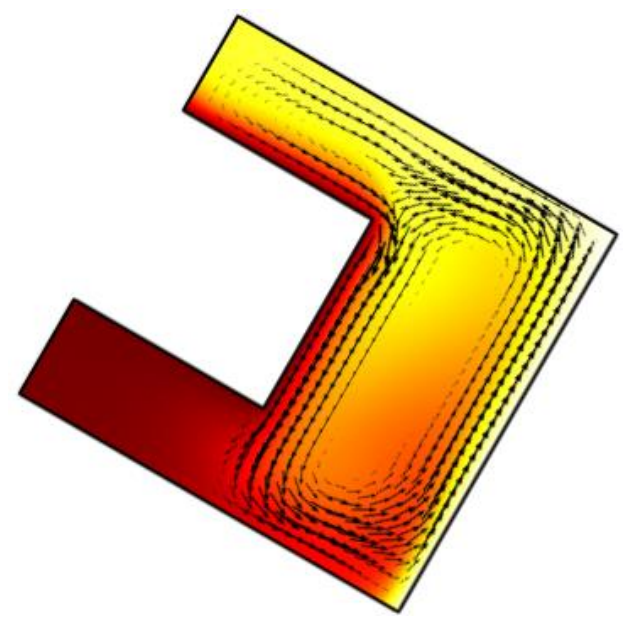

(b)

Fig. 8. Plot of velocity vectors (arrow) with (a) velocity magnitude; (b) isosurface; with $\Theta=60^{\circ}$; $H_{C}=L_{C}=0.5 ; R a=10^{6}$ and $\phi_{\mathrm{hp}}=0.06$.

at a higher velocity than the rest of the fluid. This movement causes the heat to flow inside the enclosure to form a heat pattern as shown in the isosurface in Fig. 8b. The hot fluid from the hot wall moves toward corner $\mathrm{C}$ and pushes the fluid to move to corner D, which in turn pushes the cold fluid from cold wall $\mathrm{EF}$ to move towards corner $\mathrm{F}$ and later parallel to the cold wall $\mathrm{FG}$ towards wall $\mathrm{AB}$ due to the gravity force.

Figure 9a shows the variations of average Nusselt number $\overline{N u}$ for different Rayleigh number, Ra with different enclosure inclination angle $\Theta$ at $\mathrm{L}_{\mathrm{C}}=\mathrm{H}_{\mathrm{C}}=0.4$ and $\phi_{\mathrm{hp}}=0.05$. As Ra increases, the value of $\overline{N u}$ increases accordingly due to the turbulent flow present in the enclosure, agitating the nanofluid, causing the fluid to transfer heat at a higher rate. For $\mathrm{Ra}=10^{3}$, the increase of $\Theta$ does not affect the heat transfer rate significantly. More variations of $\overline{N u}$ occurs for $\mathrm{Ra} \geq 10^{4}$, where the turbulent flow becomes more dominant. The highest

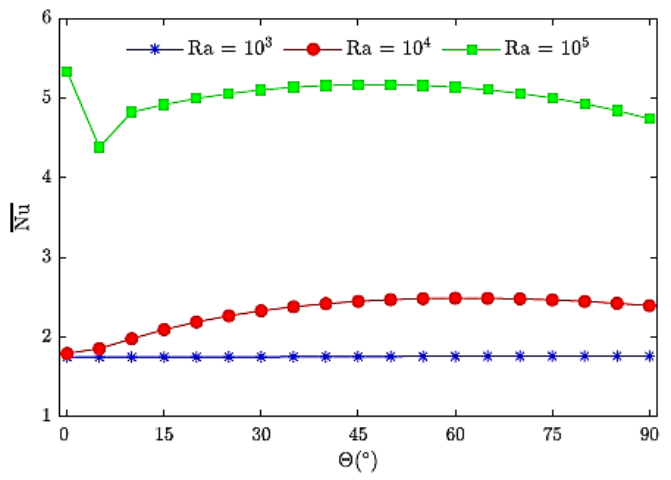

(a)

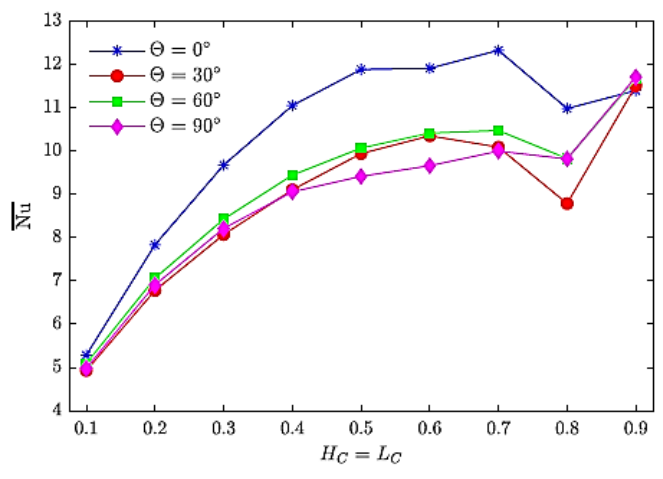

(b)

Fig. 9. Variations of average Nusselt numbers at the hot wall for (a) different Rayleigh numbers with different inclination angles at $\mathbf{H}_{\mathrm{C}}=\mathrm{L}_{\mathbf{C}}=\mathbf{0 . 4}$ and $\phi_{\mathrm{hp}}=0.05$; (b) different inclination angles with different cold rib dimensions at $\mathrm{Ra}=10^{6}$ and $\phi_{\mathrm{hp}}=\mathbf{0 . 0 5}$.

$\overline{N u}$ for $\mathrm{Ra}=10^{4}$ is around $40^{\circ} \leq \Theta \leq 70^{\circ}$, when the diagonal of the enclosure is at the same directions of buoyancy force and force due to gravity. For Ra $=10^{5}$, the highest $\overline{N u}$ occurs at $\Theta=0^{\circ}$, before decreases sharply at $\Theta=5^{\circ}$. The heat transfer rate then increases back for $\Theta \geq 10^{\circ}$ and achieve a peak at around $40^{\circ} \leq \Theta \leq 50^{\circ}$ before decreases. Figure $9 \mathrm{~b}$ shows the variations of average Nusselt number $\overline{\mathrm{Nu}}$ for different inclination angle $\Theta$ with different cold rib dimension when $\mathrm{Ra}=10^{6}$ and $\phi_{\mathrm{hp}}=0.05$. The highest value of $\overline{N u}$ is when $\Theta=0^{\circ}$ overall due to the presence of two symmetrical Rayleigh-Benard cells and increases the heat transfer rate. For all $\Theta$, the value of $\overline{N u}$ decreases at $\mathrm{L}_{\mathrm{C}}=\mathrm{H}_{\mathrm{C}}=0.8$, then increases sharply for $\mathrm{L}_{\mathrm{C}}=\mathrm{H}_{\mathrm{C}}=0.9$. This is because the space available for the fluid is just enough to inhibit the heat transfer inside the enclosure.

Figure 10 presents the variations of local Nusselt number $\mathrm{Nu}_{\text {loc }}$ at the hot wall with different inclination angle $\Theta$ at $\mathrm{H}_{\mathrm{C}}=\mathrm{L}_{\mathrm{C}}=0.4$ and $\phi_{\mathrm{hp}}=0.05$ for $\mathrm{Ra}=10^{3}$ and $\mathrm{Ra}=10^{5}$. It can be seen that the 


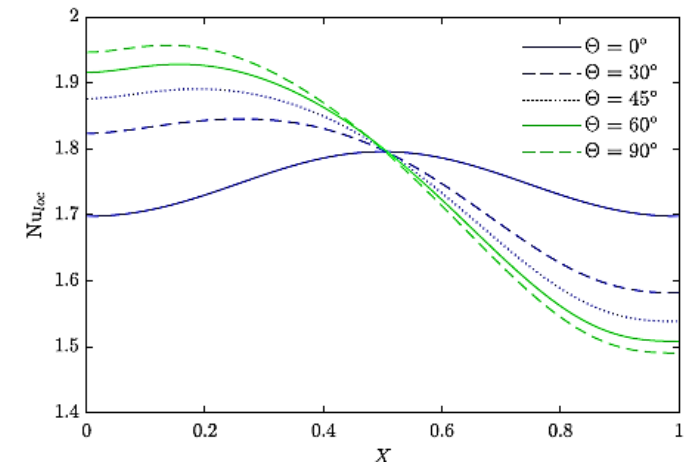

(a)

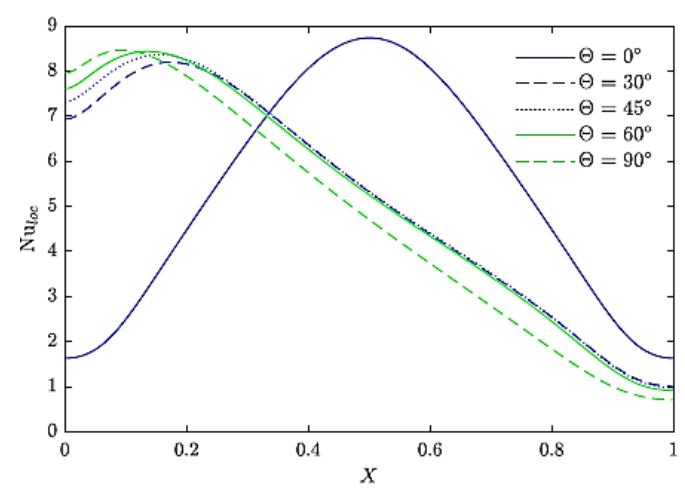

(b)

Fig. 10. Variations of local Nusselt numbers at the hot wall with different inclination angles at $\mathrm{H}_{\mathrm{C}}=\mathrm{L}_{\mathrm{C}}=0.4$ and $\phi_{\mathrm{hp}}=0.05$ for $(\mathrm{a}) \mathrm{Ra}=\mathbf{1 0}^{3}$; (b)

$$
\mathbf{R a}=10^{5} \text {. }
$$

peak of $\mathrm{Nu}_{\text {loc }}$ shifted from the center to the left side of the hot wall as $\Theta$ increases due to the changing direction of the buoyancy force although the peak is not obvious for $\mathrm{Ra}=10^{3}$. For $\mathrm{Ra}=10^{3}$ (Fig. 10a), the value of $\mathrm{Nu}_{\text {loc }}$ is the same at $\mathrm{X}=0.5$ for all $\Theta$ due to the laminar flow of the fluid. As Ra increases, the turbulent flow causes the heat transfer to peak at around $0.1 \leq X \leq 0.2$ and decreases constantly throughout the hot wall. At the center part of the hot wall, the value of $\mathrm{Nu}_{\text {loc }}$ is not affected by $\Theta$ as shown in Fig. 10b.

Figure 11 presents the variations of local Nusselt number $\mathrm{Nu}_{\text {loc }}$ at the cold wall with different cold inclination angle at $\mathrm{H}_{\mathrm{C}}=\mathrm{L}_{\mathrm{C}}=0.4$ and $\phi_{\mathrm{hp}}=0.05$ for $\mathrm{Ra}=10^{3}$ and $\mathrm{Ra}=10^{5}$. It is noted that the highest value of $\mathrm{Nu}_{\text {loc }}$ is at the corner $\mathrm{F}$ for both $\mathrm{Ra}$. The value of $\mathrm{Nu}_{\text {loc }}$ is not affected by the increase of $\Theta$ for $\mathrm{Ra}=10^{3}$ (Fig. 11a) due to the laminar flow of the fluid. The more obvious difference of $\mathrm{Nu}_{\text {loc }}$

is shown for $\mathrm{Ra}=10^{6}$ at Fig. $11 \mathrm{~b}$, where the highest value of $\mathrm{Nu}_{\text {loc }}$ is near the corner $\mathrm{F}$. The buoyancy force dominates in this corner because it is located near the hot wall. The area also has the highest rate of heat dissipation.

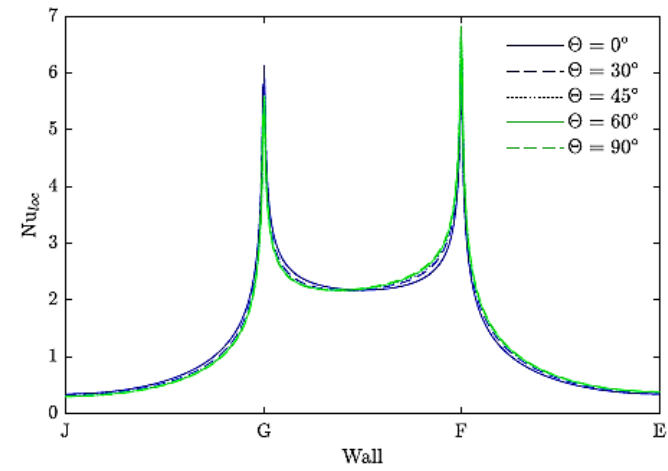

(a)

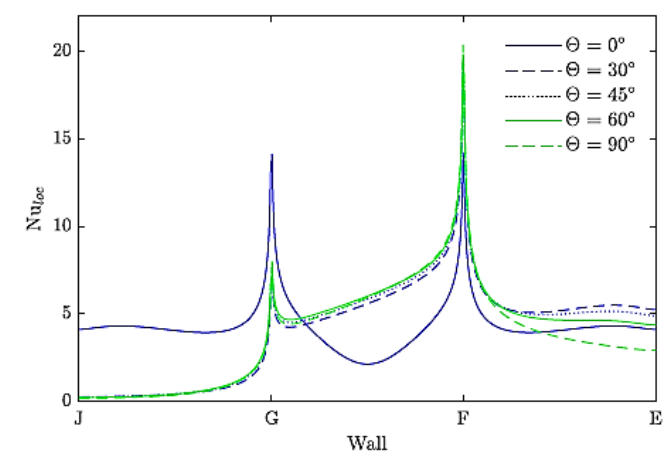

(b)
Fig. 11. Effect of the cavity inclination angle to the local Nusselt numbers at the cold wall with $\mathbf{H C}=\mathrm{LC}=0.4$ and $\phi_{\mathrm{hp}}=\mathbf{0 : 0 5}$ for (a) $\mathrm{Ra}=\mathbf{1 0}^{3}$; (b) $\mathbf{R a}=\mathbf{1 0}^{5}$.

Figure 12a and Fig. 12b show the variations of the horizontal and vertical velocity of the fluid, respectively, with different enclosure inclination angle at $\mathrm{H}_{\mathrm{C}}=\mathrm{L}_{\mathrm{C}}=0.4$ and $\phi_{\mathrm{hp}}=0.05$ for $\mathrm{Ra}$ $=10^{5}$ at $\mathrm{Y}=0.3$. It can be seen that fluid velocity is about symmetric at $\mathrm{X}=0.5$ for both horizontal and vertical velocity. For vertical velocity (Fig. 12b), the highest velocity occurred near the adiabatic wall for all $\Theta$. For horizontal velocity (Fig. 12a), the highest velocity for $\Theta=0^{\circ}$ took place at near the center of the enclosure, while for $\Theta=0^{\circ}$, the highest horizontal velocity is nearer to the adiabatic wall, and becomes closer to the center of the enclosure as $\Theta$ increases, which is in agreement as the streamlines shown in Fig. 6.

\section{Conclusion}

The numerical analysis of buoyancy-driven heat transfer of water-based hybrid nanofluid infused with $\mathrm{Cu}-\mathrm{Al}_{2} \mathrm{O}_{3}$ nanoparticles within an inclined $\mathrm{U}$ shaped cavity is presented in this paper. The following items are the summary of the work done that can be concluded in this study:

- Replacing some metallic oxide nanoparticles with metallic nanoparticles increases the heat transfer performance inside the enclosure. 


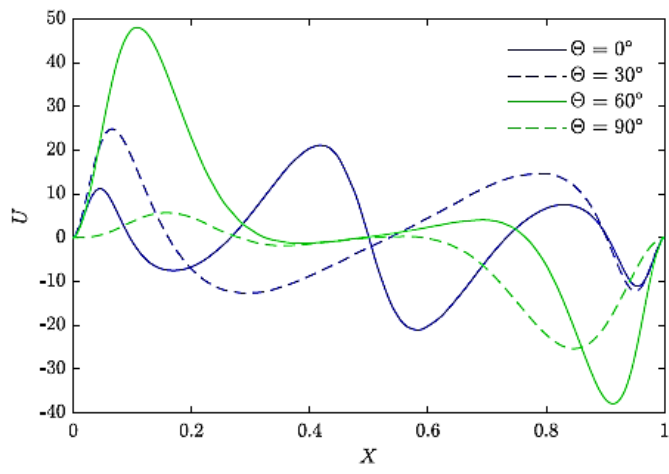

(a)

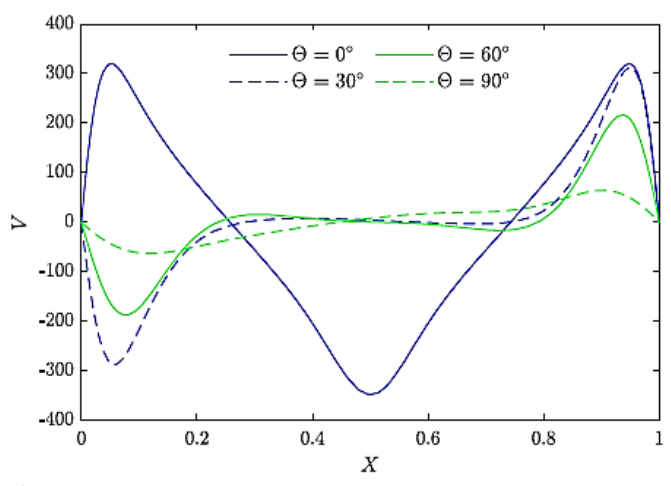

(b)

Fig. 12. Variations of (a) horizontal velocity; (b) vertical velocity; with different inclination angles with $\mathrm{HC}_{\mathrm{C}}=\mathrm{LC}_{\mathrm{C}}=\mathbf{0 . 4}$ and $\phi_{\mathrm{hp}}=\mathbf{0 . 0 5}$ for $\mathrm{Ra}=10^{6}$

$$
\text { at } \mathbf{Y}=\mathbf{0 . 3} \text {. }
$$

- As the Rayleigh number rises, a higher rate of thermal performance of the hybrid nanofluid inside the cavity is observed.

- The thermal performance of the hybrid nanofluid is directly proportional to the Rayleigh number.

- The rate of heat transfer increases as the inclination angle increases for $40^{\circ} \leq \Theta \leq 60^{\circ}$, and then decreases.

- The average Nusselt number increasing when the cold rib dimension increases except at $\mathrm{L}_{\mathrm{C}}=\mathrm{H}_{\mathrm{C}}=0.8$.

- The highest local Nusselt number is at the left area of the hot wall as the inclination angle increases.

\section{ACKNOWLEDGEMENT}

The authors would like to acknowledge the Ministry of Higher Education Malaysia for the financial support through the Fundamental Research Grant Scheme (FRGS) FP020-2020 (FRGS/1/2020/STG06/UM/02/6) and the Impact Oriented Interdisciplinary Research Grant (IIRG) IIRG006C-19IISS.

\section{REFERENCES}

Al-srayyih, B. M., S. Gao and S. H. Hussain (2019). Natural convection flow of a hybrid nanofluid in a square enclosure partially filled with a porous medium using a thermal nonequilibrium model. Physics of Fluids 31, 043609 .

Ashorynejad, H. R. (2018). MHD natural convection of hybrid nanofluid in an open wavy cavity. Results in Physics 9, 440-455.

Bhatti, M. A. (2005). Fundamental finite element analysis and applications: with Mathematica and Matlab computations. Hoboken, NJ: John Wiley \& Sons.

Brinkman, H. C. (1952). The viscosity of concentrated suspensions and solutions. The Journal of Chemical Physics 20(4), 571.

Buchanan, A. M. and A. W. Fitzgibbon (2005). Damped Newton algorithms for matrix factorization with missing data. In Proceedings of the 2005 IEEE Computer Society Conference on Computer Vision and Pattern Recognition, San Diego, CA, pp. 316-322. IEEE.

Cho, C. C., H. T. Yau and C. K. Chen (2012). Enhancement of natural convection heat transfer in a U-shaped cavity filled with $\mathrm{Al}_{2} \mathrm{O}_{3}$ water nanofluid. Thermal Science 16(5), 13171323.

Choi, S. U. S. (1995). Enhancing thermal conductivity of fluids with nanoparticles. Development and Applications of NonNewtonian Flows 231, 99-105.

Giwa, S. O., M. Sharifpur and J. P. Meyer (2020). Experimental study of thermoconvection performance of hybrid nanofluids of $\mathrm{Al}_{2} \mathrm{O}_{3}$ MWCNT/water in a differentially heated square cavity. International Journal of Heat and Mass Transfer 148, 119072.

Guestal, M., M. Kadja and M. T. Hoang (2018). Study of heat transfer by natural convection of nanofluids in a partially heated cylindrical enclosure. Case Studies in Thermal Engineering 11, 135- 144.

Hamilton, R. L. and O. K. Crosser (1962). Thermal conductivity of heterogenous two component systems. Industrial \& Engineering Chemistry Fundamentals 1(3), 187-191.

Hassan, M., M. Marin, R. Ellahi and S. Z. Alamri (2018). Exploration of convective heat transfer and flow characteristics synthesis by $\mathrm{Cu}-$ Ag/water hybrid-nanofluids. Heat Transfer Research 49(18), 1837-1848.

Hayat, T. and S. Nadeem (2017). Heat transfer enhancement with $\mathrm{Ag}-\mathrm{CuO} /$ water hybrid nanofluid. Results in Physics7, 2317-2324.

Ma, Y., R. Mohebbi, M. M. Rashidi and Z. Yang (2019). Effect of hot obstacle position on natural convection heat transfer of MWCNTs- 
M. S. Asmadi et al. / JAFM, Vol. 15, No. 2, pp. 337-348, 2022.

water nanofluid in U-shaped enclosure using lattice Boltzmann method. International Journal of Numerical Methods for Heat \& Fluid Flow 29(1), 223-250.

Makulati, N., A. Kasaeipoor and M. M. Rashidi (2016). Numerical study of natural convection of a water-alumina nanofluid in inclined $\mathrm{C}$ shaped enclosures under the effect of magnetic field. Advanced Powder Technology 27(2), 661-672.

Mohebbi, R., M. Izadi and A. J. Chamkha (2017). Heat source location and natural convection in a C-shaped enclosure saturated by a nanofluid. Physics of Fluids 29, 122009.

Roy, N. C. (2019). Flow and heat transfer characteristics of a nanofluid between a square enclosure and a wavy wall obstacle. Physics of Fluids 31, 082005.
Snoussi, L., N. Ouerfelli, X. Chesneau, A J.Chamkha, F. Muhammad Belgacem and A. Guizani (2017). Natural convection heat transfer in a nanofluid filled U-shaped enclosures: Numerical investigations. Heat Transfer Engineering 39(16), 1450-1460.

Tayebi, T. and A. J. Chamkha (2017). Buoyancydriven heat transfer enhancement in a sinusoidally heated enclosure utilizing hybrid nanofluid. Computational Thermal Sciences: An International Journal 9(5), 405-421.

Tayebi, T. and A. J. Chamkha (2020). Magnetohydrodynamic natural convection heat transfer of hybrid nanofluid in a square enclosure in the presence of a wavy circular conductive cylinder. Journal of Thermal Science and Engineering Applications 12(3), 031009. 